\title{
Algorithm for managing investment resources for enterprises' fixed assets reproduction
}

\author{
Boyko Andrei Anatolievich \\ (a) Dept. of Management \\ Siberian Federal University, \\ (b) Dept. of Management \\ Reshetnev Siberian State University of Science and \\ Technology \\ Krasnoyarsk, Russia
}

\author{
Kukartsev Vladislav Viktorovich \\ (a) Dept. of Informatics \\ Siberian Federal University, \\ (b) Dept. of Information Economic Systems \\ Reshetnev Siberian State University of Science and \\ Technology \\ Krasnoyarsk, Russia
}

Tynchenko Vadim Sergeevich

(a) Dept. of Production Machinery and Equipment for Petroleum and Natural Gas Engineering

Siberian Federal University,

(b) Dept. of Information Control Systems

Reshetnev Siberian State University of Science and

Technology

Krasnoyarsk, Russia
Chzhan Ekaterina Anatolievna

Dept. of Informatics

Siberian Federal University,

Krasnoyarsk, Russia

\author{
Stupina Alena Alexandrovna \\ (a) Dept. of Economics and Information Technologies of Management \\ Siberian Federal University, \\ (b) Dept. of Systems Analysis and Operations Research \\ Reshetnev Siberian State University of Science and Technology \\ Krasnoyarsk, Russia
}

\begin{abstract}
The article deals with the algorithm for managing the formation of investment resources for the reproduction of the main production assets of enterprises, as well as setting the task of determining the optimal structure of financing sources for enterprise projects on the basis of linear programming. In order to solve this problem, it is necessary to use instrumental management methods to increase the efficiency of decisions taken by investment managers to form an optimal structure of sources of financing for the company's projects. The most developed and widely used economic-mathematical method for solving problems of optimal planning is linear programming. As a result of the optimization criteria analysis for compliance with the requirements, it was established that only the criterion of minimization of the average weighted cost of the enterprise's capital meets them to the full. The criterion "minimization of the weighted average cost of capital" makes it possible to optimize the structure, both of the enterprise's total capital, and the structure of sources of investment resources for the reproduction of the company's fixed productive assets. And it also takes into account indirectly the level of risk through the cost of attracted investment resources from various sources.
\end{abstract}

Keywords-investment resources, main production assets renewal, average capital cost, lineal programming.

\section{INTRODUCTION}

In the process of managing the formation of investment resources for the reproduction of the main production assets (MPA) of machine-building enterprises, because of the limited investment resources of the reproduction of the investment fund, investment managers are faced with the problem of choosing the optimal structure for their formation. The complexity of this problem is due to the variety of sources of investment resources (own, borrowed, etc.) and a variety of factors affecting the choice of sources of investment resources (investment risks, the company's own financial potential, the cost of attracting investment resources from various sources, etc.).

Building up the optimum structure of enterprise's project financing sources, i.e. setting up the most profitable ratio between own and borrowed financing sources actually makes up the so called "royal problem" (das Königsproblem) of financial management $[1,2]$.

While having the above task resolved, managers face the number of complex problems: determination of required 
investment sources volume to implement projects, analysis of quite a number of their financing sources, peculiarity analysis of each specific source, analysis of factors restricting the engagement of investment resources from these channels as well as determination of financing sources cost $[3,4,5]$.

\section{THE STRUCTURAL AND FUNCTIONAL MODEL OF INVESTMENT FUNDS GENERATION}

Based on the standard for modeling business processes IDEF0 [5,6] and using the software AllFusion Process Modeler (BPwin), a structural and functional model of the process of formation of investment resources for the reproduction of fixed assets of the enterprise was developed, the description of which is given below.

The process of modeling a system in IDEF0 begins with the definition of the context, i.e. the most abstract level of the system description. The context includes the definition of the modeling area, the goal and the point of view of the model $[5,7]$.
The scope of the research in this work is limited to the process of forming investment resources for the reproduction of the enterprise's MPA, at the input of the process we have the volume of necessary investment resources for the planned time periods, and at the output we must obtain the optimal structure of the sources of investment resources. The aim of modeling is to build a structural and functional model of the process of forming investment resources for the development of an information management system for this process. The process of formation of investment resources is considered from the point of view of the investment manager, who takes decisions on this process. After defining the context, we go directly to the construction of the model.

The model in IDEF0 notation is a collection of hierarchically ordered and interconnected diagrams. The top of the tree structure of diagrams is the context diagram, which is the most general description of the system and its interaction with the external environment [6]. Figure 1 shows a contextual diagram of the process of formation of investment resources.

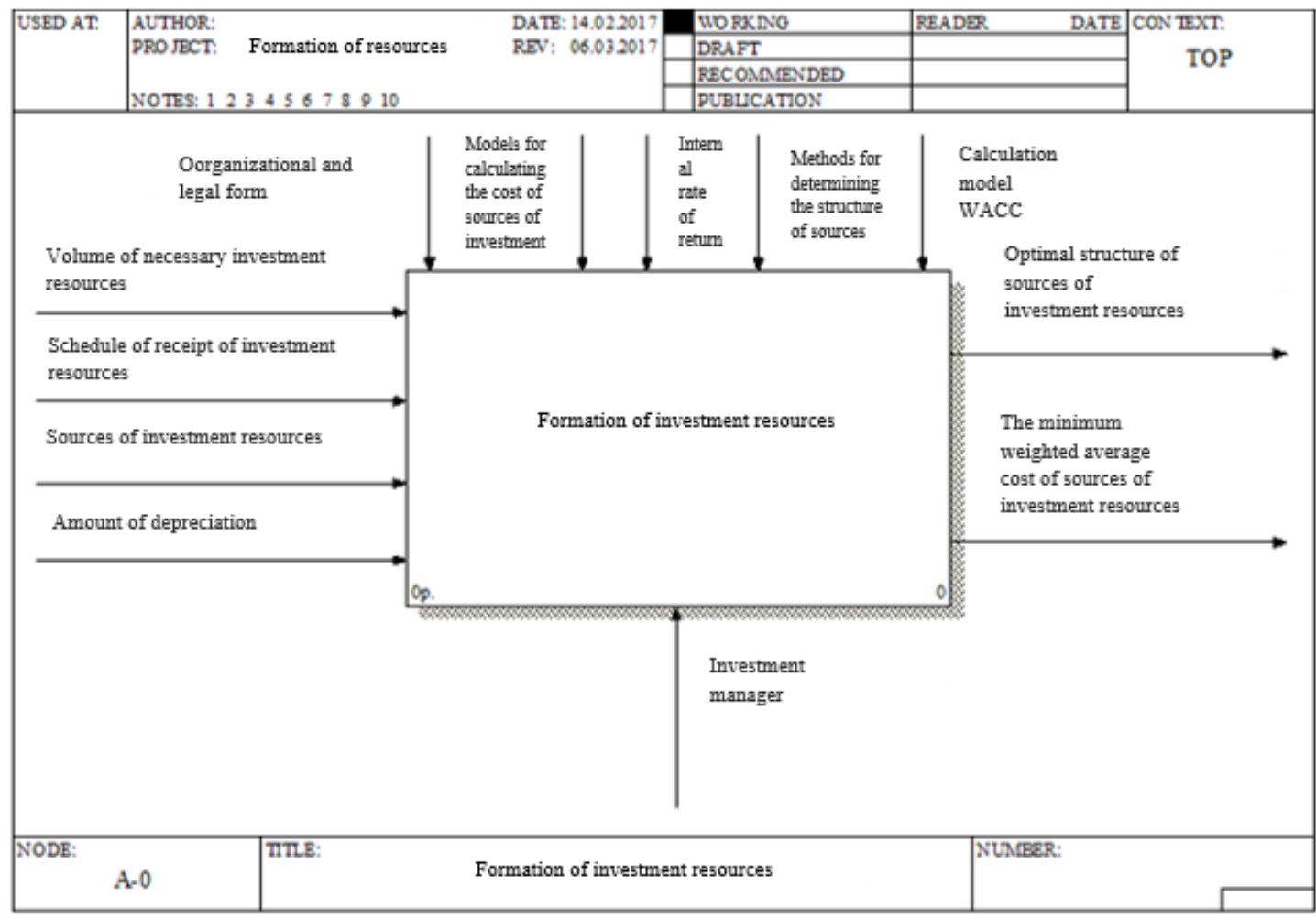

Fig. 1. Context diagram of investment resources formation

Figure 2 shows the decomposition of the context diagram described above. The context diagram is reduced to four business processes: determination of available sources of investment resources, calculation of the cost of sources of investment resources, calculation of the average cost of sources of investment resources and calculation of investment potential $[3,4]$. Business processes in the diagram are presented in order of dominance. In the upper left corner there is a business process that is executed first by time. Further down the right, there are the later running business processes. In the decomposition diagram, business processes are numbered according to the execution time. 


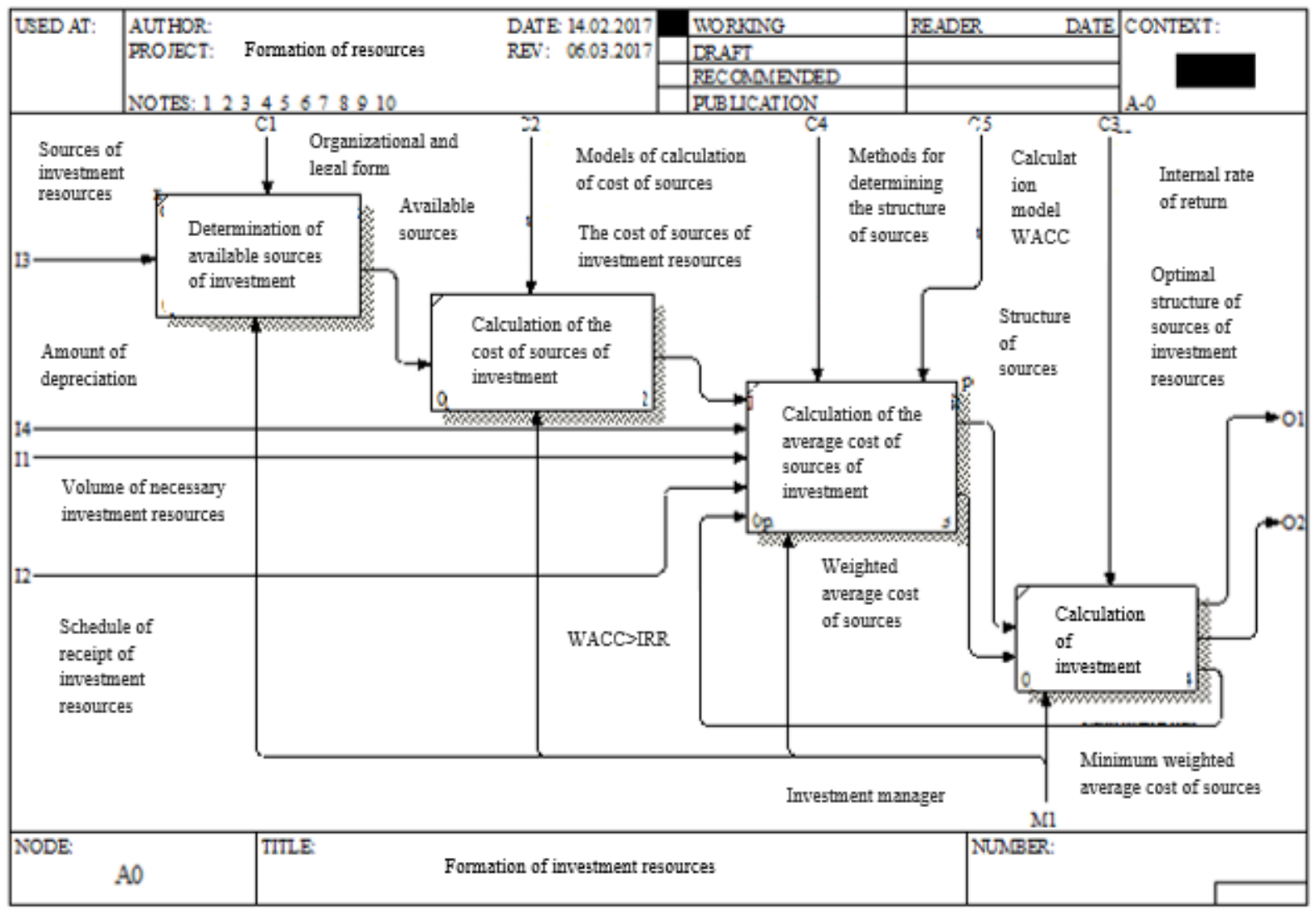

Fig. 2. Decomposition of the contextual diagram of the investment resources formation

The input parameters of the process are: the volume of investment resources required, the schedule for the receipt of investment resources broken down over the intervals of the planned period, the sources of investment resources are cash (depreciation, profit, credit, etc.) and capital assets (for leasing, etc.) $[3,4]$.

At the output of the process, as a result of the transformation of the input resources, we obtain the following parameters: the optimal structure of the sources of investment resources, which provides the minimum value of the weighted average cost of capital.

Transformation of the input parameters occurs under the influence of the following control parameters: organizational and legal form, models for calculating the cost of sources of investment resources, the norms of internal profitability and methods for determining the structure of sources of investment resources.

As the mechanism for the implementation of the process, the decision-maker (the investment manager) acts. After describing the system as a whole, it is divided into large fragments. This process is called functional decomposition, and the diagrams that describe each fragment and interaction of fragments are called decomposition diagrams [5].

To have the above problems resolved, it is necessary to use management tools such as economic-mathematical modelling that increase the efficiency of investment management decisions aimed at building up the optimum structure of enterprise's project financing sources $[6,7]$.

\section{RESULTS AND DISCUSSION}

One of the most developed and widely used economicmathematical methods of optimum planning task solution is lineal programming. It is provided by:

- Mathematics models of many economic tasks that are lineal against sought variables.

- The tasks that are most explored at the present time.

- Some tasks that are not lineal initially could become lineal after additional transformations.

Let us now go to setting the task of enterprise's optimum structure of project financing sources de-termination by ways of lineal programming.

Economic-mathematical modelling of any lineal programming task starts with target function deter-mination. In the course of target function determination it is as a rule necessary to find the optimum value of some parameter (optimality criterion), which determines the solution of a given task. While forming the enterprise's optimum structure of project financing sources, the issues of the resources structure and appropriate payment for the above resources are being resolved as payment of interest resulting from investment resources requires to take into consideration enterprise's 
financial potential as well as the risks arising from investment resources involvement. Then, the major requirements to the enterprise's optimum structure of project financing sources selection will be as follows [8]:

- Investment resources structure optimization by different channels of their attraction.

- Consideration of a risk level when attracting investment resources through various channels.

- Consideration of their cost.

- Consideration of own financial potential of an enterprise.

Modern economic literature suggests the following criterion of enterprise's optimum structure of project financing sources formation:

- Criterion of enterprise's cost effectiveness level maximization.

- Criterion of financial risks level minimization.

- Criterion of weighted average cost of capital (WACC) minimization.

Having these criteria analyzed in order to meet requirement determined above to optimize the enterprise's optimum structure of project financing sources, the criterion of WACC was selected $[9,10]$.

The criterion "minimization of the average weighted cost of capital" makes it possible to optimize the structure, both of the enterprise's total capital, and the structure of sources of investment resources for the reproduction of the enterprise's MPA. It takes into account the level of risk through comparison of the weighted average cost of capital and profitability of the enterprise. The enterprise must ensure the profitability of its activities not lower than the weighted average cost of capital. And also takes into account indirectly the level of risk through the cost of attracted investment resources from various sources. This criterion allows differentiating the cost of attracting investment resources, both from own and borrowed sources. It also takes into account its own financial potential by comparing the weighted average cost of capital and the level of profitability of the enterprise.

Then, the target function will look as follows. Let us find the minimum value of WACC:

$$
W A C C=c_{1} w_{1}+c_{2} w_{2}+\ldots+c_{n} w_{n} \rightarrow \min ,
$$

where $c_{i}-$ cost $i$ - of that project financing source;

$w_{i}$ - weighted average $\mathrm{j}$ - of that project financing source.

The target function restrictions system consists of the following equations:

$$
\left\{\begin{array}{c}
\sum_{j=1}^{n} w_{j}=100 \% \\
W A C C \leq R \\
\mathrm{c}_{i} \geq 0 \\
w_{j} \geq 0 \\
w_{j} \leq W_{j},
\end{array}\right.
$$

where $\sum_{j=1}^{n} w_{j}=100 \%$ - total weighted average of all project financing sources cannot exceed $100 \%$;

$W A C C \leq R-$ WACC must be less or equal to enterprise's implemented projects cost effectiveness;

$c_{i} \geq 0-$ cost of financing source cannot be negative;

$w_{i} \geq 0$ - share of financing source cannot be negative;

$w_{i} \leq W_{i}-$ share restriction $j$ of that project financing source.

The internal rate of return (IRR) is calculated from the expression:

$$
N P V=-I C+\sum_{i=1}^{n} \frac{C F_{t}}{(1+I R R)^{t}}=0
$$

or

$$
I C=\sum_{i=1}^{n} \frac{C F_{t}}{(1+I R R)^{t}}
$$

Here $N P V$ - net present value;

$C F_{t}$ - cash flows of the project by periods;

$I C$ - investments in the project at the stage of entry (launch)

Nevertheless, some major problems could make the solution of this task rather complex. They are: own capital structure heterogeneity, some sources cost increase along with increase of their volume, multiple methods of some sources share determination (weighing problem), different approaches to determine actual capital size - market value or net assets value, necessity to take depreciation deduc-tions into account.

The presented economic-mathematical model of lineal programming assists investment managers in the process of forming investment resources of the enterprise's capital assets renewal process.

Below you will find a control flow chart of this process management (Figure 1):

Step 1. Setting input information: investment sources channels, depreciation deductions volume, required investment resources volume, investment resources coming schedule, etc. $[11,12]$

Step 2. Determination of internal investment resources volume. Determination of internal invest-ment resources volume $Q_{\text {own }}$, such as depreciation deductions, capitalized profit, earnings from out-going fixed assets [13, 14]. 


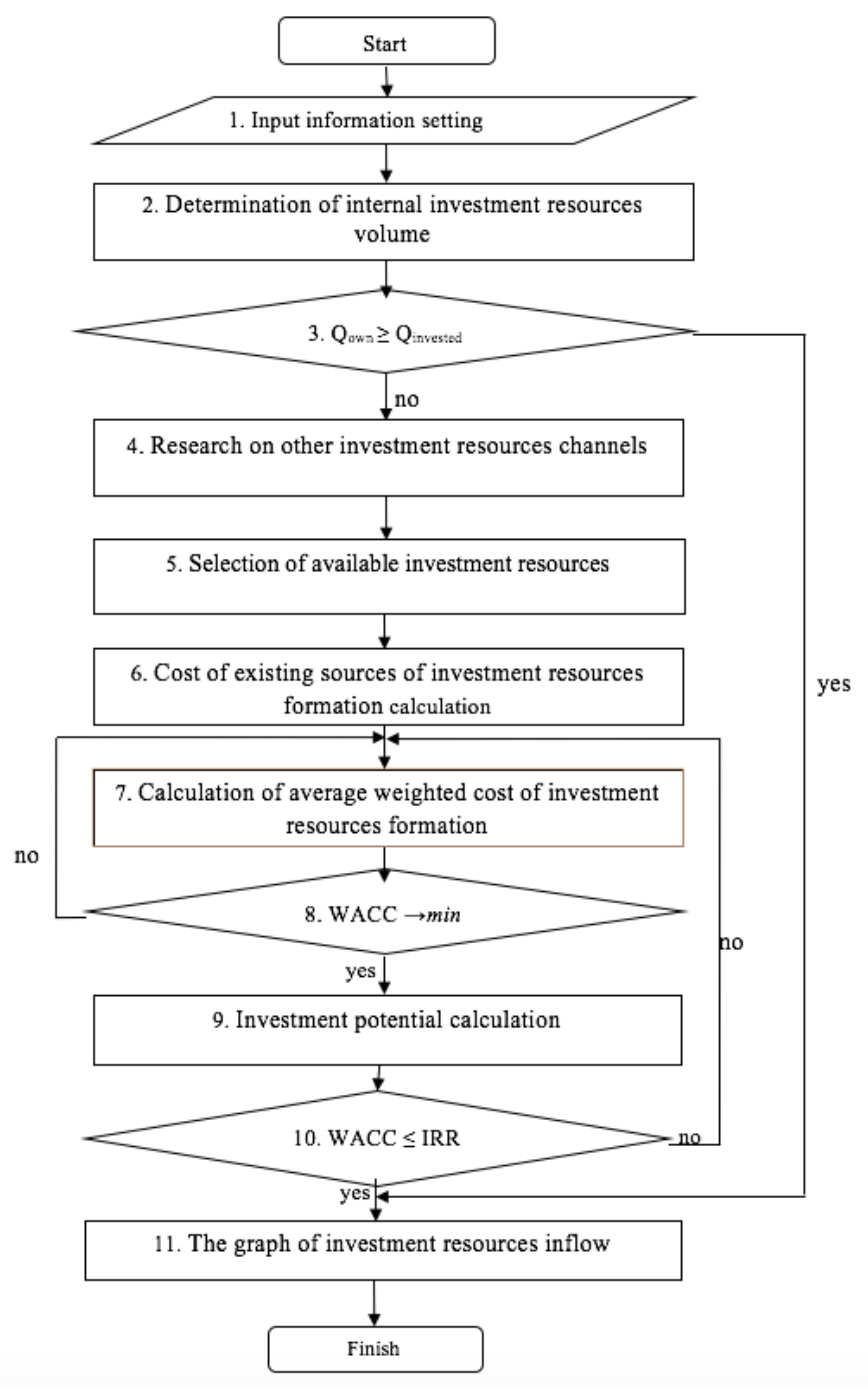

Fig. 3. Flow chart of investment resources formation algorithm

Step 3. Examination of the following condition compliance: if internal assets are sufficient enough to cover the required investment resources volume for the selected renewal variant: $Q_{\text {own }} \geq Q_{\text {invested }}$. If the above condition is met, it is necessary to go to step 9 . In case it is not met, go to step 4.

Step 4. Research on other investment resources channels. At this step the list of all existing sources of investment resources is put up together. The following major investment resource channels are considered: own external, debt. As a result, the list of all existing sources of investment resources is put up together [15].

Step 5. Selection of available investment resources. At this step, the selection of available invest-ment resource appropriate for a certain legal form of an enterprise is being made. In case investment resource meets restrictions, it is necessary to go to step 6 .

Step 6. Cost of existing sources of investment resources formation is calculated. This calculation is made according to cost of sources of the investment channel calculation model [16].

Step 7. Calculation of average weighted cost of investment resources formation. This calculation is made based on the WACC model.

Step 8. Selection of the investment resource channel structure meeting the criterion $W A C C \rightarrow \min$.

Step 9. Investment potential calculation. At this step, IRR of the project is calculated.

Step 10. At step 10, IRR of the project is compared to average weighted cost of investment resources formation. In case, IRR is lower than average weighted cost of investment resources formation, go back to step 7 and recalculate the structure and average weighted cost of investment resources formation continuing like this till we reach an opposite result. In case $I R R$ is bigger or equals average weighted cost of investment resources formation, the calculation is finished and the outcome is the optimum structure of investment resources formation and the minimum average weighted cost of investment resources formation.

Step 11. The graph of investment resources inflow is made.

Thus, the suggested methodology of enterprise's management algorithm of investment resources formation of MPA renewal allows one to make weighed and grounded management decisions on such resources formation.

\section{CONCLUSION}

As a result of the analysis of the optimization criteria for compliance with the requirements, it was established that only the criterion of minimization of the average weighted cost of the enterprise's capital meets them to the full.

The criterion "minimization of the average weighted cost of capital" makes it possible to optimize the structure, both of the enterprise's total capital and the structure of sources of investment resources for the reproduction of the enterprise's main production assets. Also, algorithm takes into account indirectly the level of risk through the cost of attracted investment resources from various sources and own financial potential of the enterprise.

\section{References}

[1] M.A. Stolyarova, O.L. Shulgaty, M.R. Dzagoeva, L.I. Bestaeva, and V.A. Kaitmazov, "Generalization of foreign experience in the reproduction and recording of fixed assets," International Journal of Applied Business and Economic Research, vol. 12 (15), 2017, pp. 241250.

[2] A.V. Kukartsev, and K.I. Gorlevskiya, "Principles of management of innovative business processes of the enterprise of the space-rocket industry," Economy and management of control systems, vol. 1 (11), 2014, pp. 044-052.

[3] I.V. Oliynyk, "Fixed assets management in the frameworks of classical and contemporary theories," Actual Problems of Economics, vol. 6 (168), 2015, pp. 47-53.

[4] A.V. Kukartsev, K.I. Gorlevskiya, and I.V. Ogurchenok, "Management of innovative activity of the enterprise of the space-rocket industry on 
the basis of process approach," Economy and management of control systems, vol. 11, 2014, pp. 358-367.

[5] K.I. Gorlevskiya, I.V. Ogurchenok, and A.V. Kukartsev, "Scientific approaches to management of business processes of the enterprise of the space-rocket industry," Current problems of aircraft and astronautics, vol. 2 (10), 2014, pp.113-114.

[6] A.A. Boyko, V.V. Kukartsev, K.Y. Lobkov, and A.A. Stupina, "Strategic planning toolset for reproduction of machine-building engines and equipment," J. Phys.: Conf. Ser., in press.

[7] A.A. Stupina, A.A. Shigina, A.O. Shigin, M.V. Karaseva, and S.N Ezhemanskaja, "Automated intellectual system with the short-duration nature of feedback," Life Science, vol. 11, 2014, pp. 302-306.

[8] K.I. Gorlevskiya, and A.V. Kukartsev, "Regulation of innovative business processes of the enterprise of the space-rocket industry," Bulletin of the Siberian state space university of the academician M.F. Reshetnev, vol. 1 (53), 2014, pp. 194-198.

[9] J.L. Gissel, "A case of fixed asset accounting: Initial and subsequent measurement," Journal of Accounting Education, vol. 37, 2016, pp. 6166.

[10] Y. Vertakova, S. Klevtsov, M. Klevtsova, "Technology of fixed assets assessment in investigating the stability of the industrial complex of the region," Proceedings of the 26th International Business Information Management Association Conference - Innovation Management and Sustainable Economic Competitive Advantage: From Regional Development to Global Growth (IBIMA 2015), 2015, pp. 3230-3236
[11] L. Ye, "Research on enterprise fixed assets management based on KMEANS clustering algorithm," Agro Food Industry Hi-Tech, vol. 3 (28), 2017, pp. 2540-2544.

[12] K.I. Gorlevskiya, I.V. Ogurchenok, and A.V. Kukartsev, "Control algorithm of innovative business processes of the enterprise of the space-rocket industry," Bulletin of the Siberian state space university of the academician M.F. Reshetnev, vol. 2 (54), 2014, pp. 158-164.

[13] H.M. Nijam, "Motives for Reporting Fixed Assets at Revalued Amount: Evidence from a Developing Economy," Global Business Review, vol. 3 (19), 2018, pp. 604-622.

[14] G.S. Klychova, A.R. Zakirova, K.Z. Mukhamedzyanov, E.R. Sadrieva, and A.S. Klychova, "Development of audit system for operations with fixed assets as a tool for efficiency improvement of social activity of the enterprise," Journal of Engineering and Applied Sciences, vol. 12 (19), 2017, pp. 4966-4973.

[15] A.V. Kukartsev, and K.I. Gorlevskiya, "Instruments of management of business processes of the enterprise of the space-rocket industry in the competitive environment," Modern competition, vol. 5 (41), pp. 081 091.

[16] M.D. Mattei, N. Mattei, "Analysis of fixed and biased asset allocation rebalancing strategies," Managerial Finance, vol. 1 (42), 2016, pp. 42 50 . 